\title{
Insertion reactions in advanced electrochemical energy storage
}

\author{
Jürgen Otto Besenhard and Martin Winter \\ Institute for Chemical Technology of Inorganic Materials, Stremayrgasse 16/III \\ and SFB Electroactive Materials, \\ Technical University of Graz , A-8010 Graz, AUSTRIA
}

\begin{abstract}
A rechargeable electrochemical energy storage system employing an organic solvent-based electrolyte will be introduced: the lithium-ion cell. The electrode reactions base on $\mathrm{Li}^{+}$-insertion/-removal which ensure high rechargeability. The system possesses an operating voltage of $\sim 3.5 \mathrm{~V}$ and a high energy density. From a thermodynamic viewpoint such a cell is impossible because the used organic electrolyte is in contact with two electrodes that operate at extreme reducing $\left(\sim+0.1 \mathrm{~V}\right.$ vs. $\left.\mathrm{Li} / \mathrm{Li}^{+}\right)$and oxidizing $\left(\sim+4.5 \mathrm{~V}\right.$ vs. $\left.\mathrm{Li}^{\prime} / \mathrm{Li}^{+}\right)$potentials, respectively. However, lithium-ion cells perform successfully because a unique mechanism kinetically prevents the decomposition of electrolyte due to the formation of electronically insulating electrode/electrolyte interfaces that are still permeable to the electrochemically active $\mathrm{Li}^{+}$-cations.
\end{abstract}

\section{Introduction}

In the late 19 th and early 20 th century electrochemistry was dominated very much by electrochemical thermodynamics. The names of James Prescott Joule (1818-1898), Wilhelm Ostwald (1853-1923), and Walther Nernst (1864-1941) may be representative for those researchers who developed and proved fundamental ideas which are still valid. However, electrochemistry is first and foremost a branch of surface science. This is also true for the field of electrochemical energy storage which might be considered as mostly controlled by thermodynamics, because "reversibility" is required or at least desired. As a matter of fact, most of our technical electrochemical energy storage systems operate outside the limitations of thermodynamics as is demonstrated by the cell voltages more or less above the decomposition voltage of water which is $1.23 \mathrm{~V}$ at room temperature (for instance, in the commonly known lead acid accumulator cell voltages of $\sim 2 \mathrm{~V}$ ). This paper will focus on a new class of organic electrolyte electrochemical energy storage systems characterized by voltages up to $\sim 4.5 \mathrm{~V}$ per single cell. The unique mechanism preventing the decomposition of electrolyte expected under these conditions will be discussed in detail.

\section{Light metals as negative battery electrode materials}

The galloping proliferation of modern technologies, like portable consumer electronic products or electric vehicles, has generated the need for advanced electrochemical energy storage systems that provide both, high energy density and multiple rechargeability. In order to accomplish such high energy density batteries the use of high capacity materials for both the negative and the positive electrode is inevitable. Considering thermodynamic reasoning for the selection of a negative electrode material, light metals $\mathrm{M}$, like $\mathrm{Li}, \mathrm{Na}, \mathrm{K}$ or $\mathrm{Mg}$, are favored as they combine outstanding negative standard redox potentials with low 
equivalent weights. However, a realization of batteries using these metals as active material is usually not possible because the strong reducing power of these metals results in a spontaneous reaction in contact with an electrolyte.

Among the light metals $\mathrm{M}$ metallic lithium fortunately shows a unique corrosion behavior which favors its use in a high energy density battery. In suitable nonaqueous electrolytes, "passivating" films of $\mathrm{Li}^{+}-$ containing electrolyte decomposition products, spontaneously formed upon the immersion in the electrolyte protect the lithium surfaces. These films act as a sieve for the electrochemically active charge carriers $\mathrm{Li}^{+}$, i.e. as a electronically insulating solid electrolyte interface (SEI) being selectively permeable to $\mathrm{Li}^{+}$cations but impermeable to any other electrolyte component that would react with the lithium under the film (refs. 1,2). The composition and structure of the SEI-layers on metallic lithium are dependent on the kind of electrolyte and have been subject of many investigations (refs. 1-5). There is general agreement that the films formed in organic solvent-based electrolytes ${ }^{1}$ comprise of (i) porous organic polyand oligomeric, and (ii) compact inorganic decomposition products (Fig. 1). Electrolyte decomposition products of the other light metals $\mathrm{M}$ do not form films with equivalent properties for corrosion protection and cation transport. In some cases the solubility of the electrolyte decomposition products is too high or the mobility of the $\mathrm{M}^{\mathrm{n}+}$-cations is insufficient, or both. In particular, solid state transport of divalent cations such as $\mathrm{Mg}^{2+}$ requires high activation energies and will be extremely slow at ambient temperature (refs. $1,8-10)$. It is one of the fortuitous incidents in chemistry that the light metal with the highest capacity per weight is just the only one that is corrosion protected but still electrochemically active.

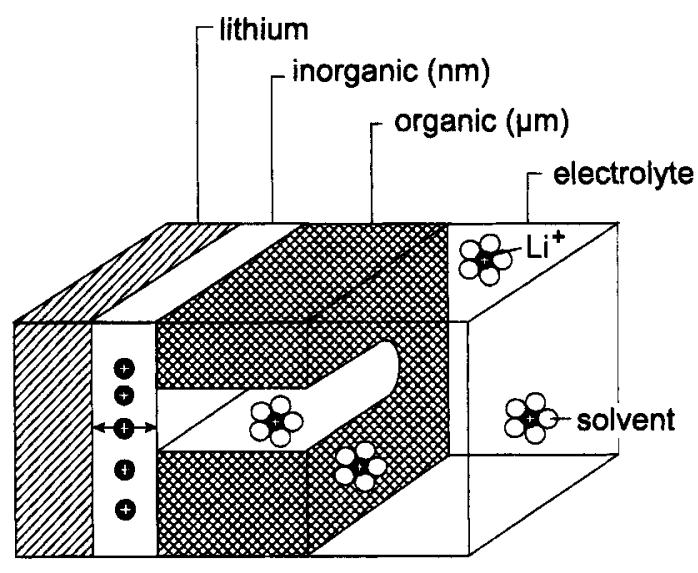

Fig. 1: Schematic representation of protection of lithium in organic solvent-based electrolytes, from (ref. 18).
The observation of the kinetic stability of lithium in a number of nonaqueous electrolytes founded the research field "lithium batteries" in the 1950 s, and the commercialization of primary (not rechargeable) lithium batteries followed quickly in the late 1960 s and early 1970 s. Today, primary metallic lithium systems have found a variety of applications, e.g. military, consumer and medical, and commercial interest is still growing (refs. 1114). However, apart from niche market products (ref. 15), the commercial breakthrough of rechargeable batteries with a lithium negative electrode failed. Upon recharge the growth of the lithium electrode occurs simultaneously with lithium corrosion and "passivation" (= formation of SEI). Lithium deposits as highly disperse, highly reactive metal particles (refs. 1,2,16). These dendrites are partly electrochemically inactive and thus cycle life is reduced. Moreover, they grow to filaments upon cycling, which may short-circuit and locally overheat the cell and cause a disastrous thermal runaway due to the low melting point of $\mathrm{Li}\left(\sim 180^{\circ} \mathrm{C}\right)$ (refs. 16,17). Thus, in commercial rechargeable lithium batteries metallic lithium is replaced by $\mathrm{Li}^{+}$-insertion materials.

\footnotetext{
${ }^{1}$ These are the commonly used electrolytes in lithium batteries comprising of lithium salts like $\mathrm{LiPF}_{6}, \mathrm{LiBF}_{4}$ or $\mathrm{LiN}\left(\mathrm{SO}_{2} \mathrm{CF}_{3}\right)_{2}$ dissolved in aprotic organic solvents like cyclic organic carbonates, acyclic organic carbonates or ethers (refs. 6,7).
} 


\section{A rechargeable lithium battery employing two insertion electrodes - the lithium-ion cell}

The operating principle of most of the advanced commercial battery systems (e.g. lithium-ion, nickel/metal-hydride or rechargeable alkaline manganese oxide) and also of some of the more conventional ones (refs. 18,19) is based on electrochemical insertion ("electroinsertion") of ions coupled with transfer of electrons. Prerequisites of these host/guest reactions are small and highly mobile guest ions, e.g. protons and $\mathrm{Li}^{+}$-cations, and mixed (= electron plus ion) conducting host materials, that are dimensionally stable during insertion and subsequent removal of guests (ref. 18,19).

The widespread battery application of the electroinsertion mechanism is related with its inherent simplicity and high rechargeability (refs. 18,19), which can be explained by the example lithium-ion cell, a rechargeable lithium cell that can provide more than 1000 charge/discharge cycles with a Faradayic efficiency $>99.9 \%$. A lithium-ion cell combines two $\mathrm{Li}^{+}$-insertion electrode materials: one having a low standard redox potential for the negative electrode and another having a distinctly higher standard redox potential for the positive electrode (refs. 20,21). There are many host matrices which can insert/remove lithium, e.g. metal oxides and chalcogenides, black carbons, metals or redox polymers (Fig. 2), so that many combinations and cell voltages are feasible in principle. In practical lithium-ion cells certain carbon based negative electrode materials, like e.g. graphite, and transition metal oxide-based positive electrode materials $\mathrm{Li}_{x} \mathrm{MO}_{2}(\mathrm{M}=$ e.g. $\mathrm{Co}, \mathrm{Ni})$ have been selected, as they provide a high cell voltage $(\sim 3.5 \mathrm{~V})$ and energy density (review refs. 14,18-24). No metallic lithium is present at any point of charge/discharge. The entire electrochemistry involves only the transfer of $\mathrm{Li}^{+}$-cations between insertion electrodes with different chemical potentials (= concentration cell, Fig. 3). Lithium-ion cells have been commercialized by several, mostly Japanese, companies.

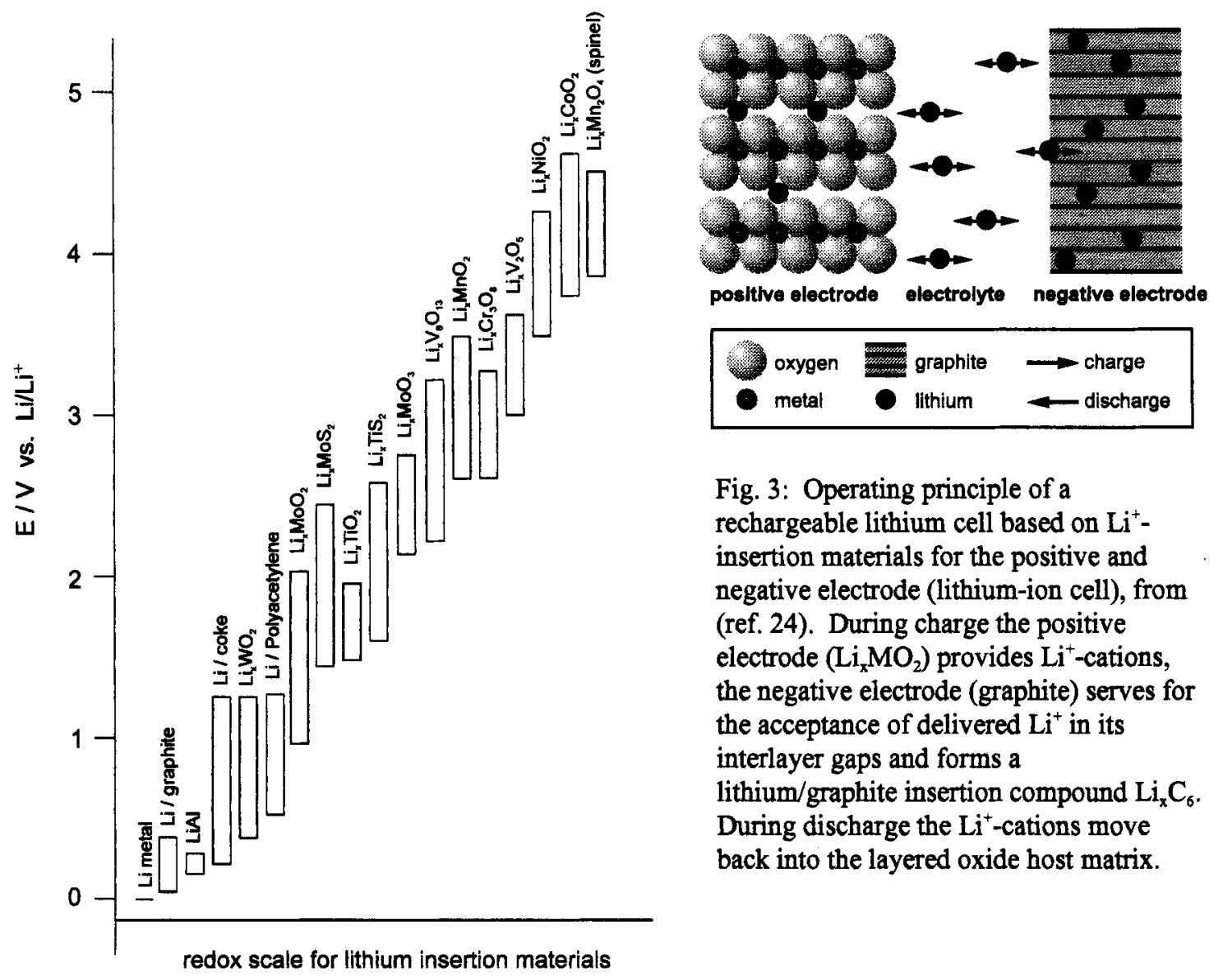

Fig. 2: Potential ranges of several lithium insertion materials. 
A typical example for an insertion electrode reaction is the electrochemical formation of lithium/graphite insertion compounds $\left(\mathrm{Li}_{\mathrm{x}} \mathrm{C}_{6}\right)$. A general feature of insertion into graphite is the stepwise formation of phases that are characterized by a periodic array of unoccupied layer gaps at a low concentration of guest (= stage formation, ref. 25). The stage index ' $s$ ' $\left(s=I-I V\right.$ for $\left.\mathrm{Li}_{x} \mathrm{C}_{6}\right)$ is equal to the number of graphene layers between two guest layers. Fig. 4 shows a schematic potential/composition curve for a constant

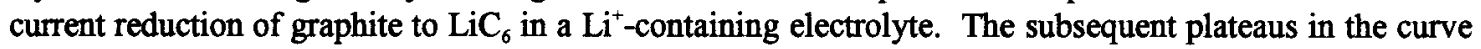
indicate two-phase regions (= coexistence of two phases) in the lithium/graphite phase diagram (ref. 26). By contrast, lithium insertion in transition metal chalcogenides, e.g. $\mathrm{TiS}_{2}$, or oxides, e.g. $\mathrm{V}_{6} \mathrm{O}_{13}$, leads to broader phases with continuously changing composition.



Fig. 4: Schematic contant current potential/composition $\left(\mathrm{E} / \mathrm{x}\right.$ in $\mathrm{Li}_{\mathbf{x}} \mathrm{C}_{6}$ ) curve for the electrochemical lithium insertion in graphite, from (ref. 27).

\section{Electrolyte stability in lithium-ion batteries}

4-Volt lithium-ion batteries are operating far beyond the range of thermodynamic stability of any organic electrolyte and, as a consequence, irreversible electrolyte reduction and oxidation is occurring at the negative and positive electrode.

Electrolyte reduction fortunately creates a protecting SEI-film on the negative $\mathrm{LiC}_{\mathrm{n}}$ electrode (Fig. 5) which in contrast to the spontaneous film-formation on metallic Li upon contact with electrolyte, proceeds as a charge-consuming side reaction in the first few $\mathrm{Li}^{+}$-insertion/ removal cycles (see refs. 17,28). The formation of these films consumes lithium (provided from the positive electrode during charge) and electrolyte (which is reduced) irreversibly, the corresponding charge loss is commonly called "irreversible capacity". Since the positive electrode is the only lithium source in the lithium-ion cell, these losses are detrimental to the capacity of the whole cell and have to be minimized for an optimum performance.

Before the formation of a film with the aforementioned sieve characteristics, i.e. in the very first charge/discharge cycles, the electrode is not sufficiently protected against corrosion with the organic electrolyte. Thus, one major problem of graphite electrodes in the first cycles is that the insertion of $\mathrm{Li}^{+}$ from organic donor solvent electrolytes proceeds together with the organic solvent and yields solvated lithium/graphite insertion compounds $\mathrm{Li}_{\mathrm{x}}(\mathrm{solv})_{\mathrm{y}} \mathrm{C}_{6}$. These are always thermodynamically unstable with respect to reduction of the intercalated polar solvents (ref. 29). Thus, $\mathrm{Li}_{\mathbf{x}}(\mathrm{solv})_{\mathrm{y}} \mathrm{C}_{6}$ decomposes and forms films inside the graphite matrix, meaning additional irreversible capacity losses occur (Fig. 6 and refs. 24,28-31).

As the battery performance of graphite electrodes is strongly related to the properties of the protective films, many research activities focus on the improvement of these films by proper choice of new electrolyte components that prevent excessive solvent co-intercalation in the early stages of the first reduction of the host. Significant improvements have been made with inorganic agents such as $\mathrm{CO}_{2}$ (refs. 
32,33), $\mathrm{N}_{2} \mathrm{O}$ and $\mathrm{S}_{\mathrm{x}}{ }^{2-}$ (ref. 33). These are added to the base electrolyte to promote the formation of more compact and presumably thinner inorganic films that are more selective for unsolvated $\mathrm{Li}^{+}$-cations than orgaric film components which are supposed to be penetrated more easily by organic solvent molecules.

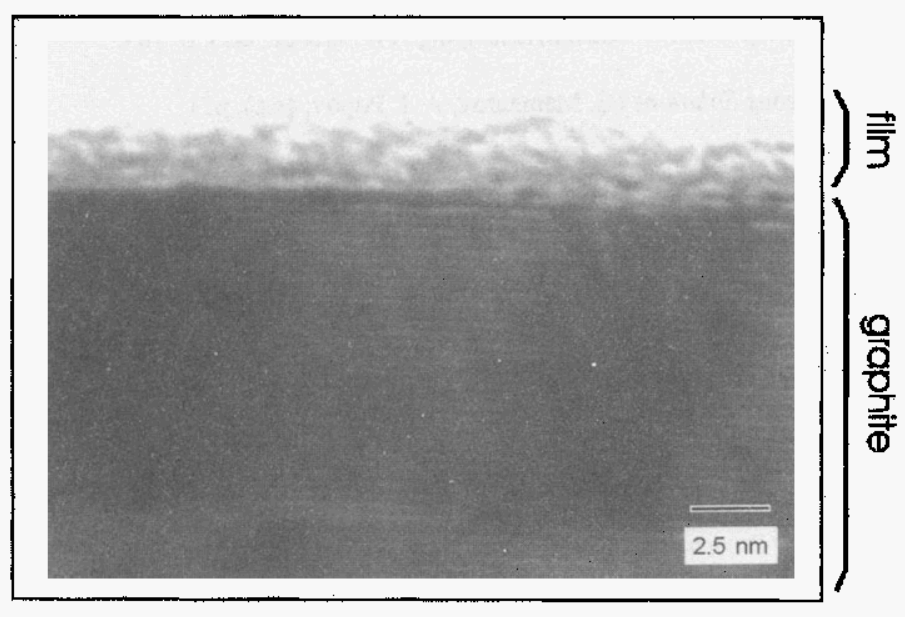

Fig. 5: TEM micrograph of SEI-filmed artificial graphite (TIMCAL KS44) in the discharged state.

Up to now there is no sufficient experimental evidence that explains the observed long-term stability of the electrolyte against oxidation at the positive electrode (the end of charge potential of the positive electrode is around $\sim 4.5 \mathrm{~V}$ vs. $\mathrm{Li} / \mathrm{Li}^{+}$, close to the potential of elementary chlorine!). From a chemists viewpoint one can hardly imagine that an organic electrolyte is thermodynamically stable on the positive electrode at these oxidizing potentials without forming an not- or at least low-electron-conducting protective interface. The nature of this interface is uncertain at present. A composition which resembles the films on the negative electrode is ambiguous, but one can assume, for instance, low electron-conductive $\mathrm{Co}$ - or $\mathrm{Ni}$-compounds. However, one analogy to the negative electrode behavior is certain without doubt. The positive electrode preserves its electrochemical activity, i.e. lithium cations can be transferred reversibly through the electrode/electrolyte interface, during cycling.

\section{Acknowledgments}

The authors are grateful to F. Hofer, FELMI Graz, for the TEM micrograph of filmed graphite. This work was partially supported by the Austrian "Fonds zur Förderung der wissenschaftlichen Forschung" (FWF) in the "Electroactive Materials" special research program. a)

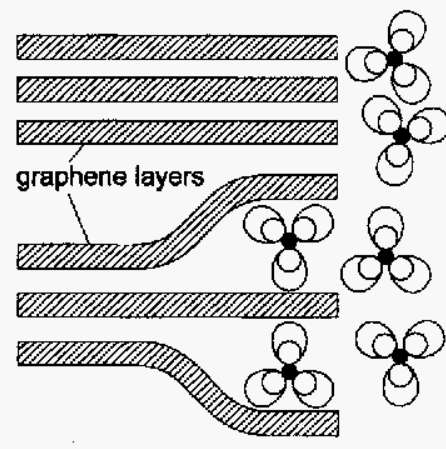

c)

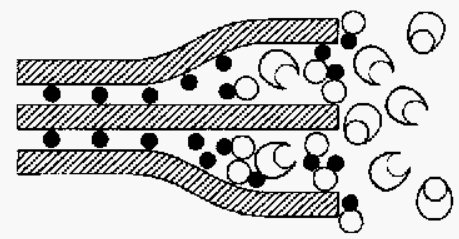

$\mathrm{RX}$ (donor solvent)

$R$ (decomposed solvent)

$\mathrm{Li}$

Lix

Fig. 6: Schematic model of the film formation mechanism on/in graphite, from (ref. 30): (a) before reaction, (b) formation of solvated lithium/graphite insertion compounds $\mathrm{Li}_{\mathrm{x}}(\mathrm{solv})_{\mathrm{y}} \mathrm{C}_{6}$, (c) filmformation due to decomposition of $\mathrm{Li}_{\mathbf{x}}$ (solv) $\mathrm{C}_{6}$. 


\section{References}

1. E. Peled. In Lithium Batteries (J.-P. Gabano, ed.), Ch. 3. Academic Press, London (1983).

2. E. Peled. J. Electrochem. Soc. 126, 40 (1979).

3. V. R. Koch. J. Power Sources 6, 357 (1981).

4. D. Aurbach, A. Zaban, Y. Gofer, Y. Ein-Eli, I. Weissman, O. Chusid and O. Abramson. J. Power Sources 54, 76 (1995).

5. J. O. Besenhard. In 8. Internationales Technisches Symposium "Notstromversorgung" (W. Jacobi., ed.), p. 189. Eurokongress, München (1993).

6. J. Barthel and H.-J. Gores. In Chemistry of Nonaqueous Solutions (G. Mamantov, A. I. Popov, eds.), p. 1. VCH, Weinheim (1994).

7. L. A. Dominey. In Lithium Batteries, New Materials, Developments and Perspectives (G. Pistoia, ed.), p. 137. Elsevier, Amsterdam (1994).

8. A. Brenner. In Advances in Electrochemistry and Electrochemical Engineering Vol. 5 (C. W. Tobias, ed.), p. 205. Interscience Publishers, New York (1967).

9. K. M. Abraham. Solid State Ionics 7, 199 (1982).

10. L. P. Lossius and F. Emmenegger. Electrochim. Acta 41, 445 (1996).

11. C. D. S. Tuck (ed.). Modern Battery Technology. Ellis Horwood Ltd., Chichester (1991).

12. D. Linden (ed.). Handbook of Batteries. McGraw-Hill, New York (1995).

13. J.-P. Gabano (ed.). Lithium Batteries. Academic Press, London (1983).

14. K. Brandt. Solid State Ionics 69, 173 (1994).

15. P. Dan, E. Mengeritsky, Y. Geronov and D. Aurbach. J. Power Sources 54, 143 (1995).

16. S. C. Levy and P. Bro, Battery Hazards and Accident Prevention. Plenum Press, New York (1994).

17. J. R. Dahn, A. K. Sleigh, H. Shi, B. M. Way, W. J. Weydanz, J. N. Reimers, Q. Zhong, and U. von Sacken. In Lithium Batteries, New Materials, Developments and Perspectives (G. Pistoia, ed.), p.1. Elsevier, Amsterdam (1994).

18. J. O. Besenhard. In Progress in Intercalation Research (W. Müller-Wamuth, R. Schöllhom, eds.), p. 457. Khwer Academic Publishers, Dordrecht (1994).

19 J. O. Besenhard and M. Winter. In 2. Ulmer Elektrochemische Tage, Ladungsspeicherung in der Doppelschicht (W. Schmickler, ed.), p. 47. Universitätsverlag, Ulm (1995).

20. M. B. Armand. In Materials for Advanced Batteries (D.W. Murphy, J. Broadhead, B.C.H. Steele, eds.), p. 145. Plenum Press, New York (1980).

21. S. Megahed and B. Scrosati. J. Power Sources 51, 79 (1994),

22. J. O. Besenhard. In Soft Chemistry Routes to New Materials (J. Rouxel, M. Toumoux, R. Brec, eds.), p. 13. Materials Science Volumes 152-153, Trans-Tech Publications, Switzerland (1994).

23. D. Guyomard and J.-M. Tarascon. Adv. Mater. 6, 409 (1994).

24. M. Winter, J. O. Besenhard and P. Novák. GDCh-Monographie 3, 438 (1996).

25. J. O. Besenhard and H. P. Fritz. Angew. Chem. Int. Ed. Engl. 95,950 (1983).

26 J. R. Dahn. Physical Review B 44, 9170 (1991).

27. M. Winter, J. O. Besenhard, M. E. Spahr, P. Novak, in preparation.

28. R. Fong, U. v. Sacken and J. R. Dahn. J. Electrochem. Soc. 137, 2009 (1990).

29. J. O. Besenhard and H. P. Fritz. J. Electroanal. Chem. 53, 329 (1974).

30. J. O. Besenhard, M. Winter, J. Yang and W. Biberacher. J. Power Sources 54, 228 (1995).

31. J. O. Besenhard, M. Winter and J. Yang. International Workshop on Advanced Batteries (Lithium Batteries), p. 129. Osaka (1995).

32. J. O. Besenhard, P. Castella and M. W. Wagner. Mater. Sci. Forum 91-93, 647 (1992).

33. J. O. Besenhard, M. W. Wagner, M. Winter, A. D. Jannakoudakis, P. D. Jannakoudakis and E. Theodoridou. J. Power Sources 43-44, 413 (1993). 